Article

\title{
Study Preparation of Refugees in Germany: How Teachers' Evaluative Practices Shape Educational Trajectories
}

\author{
Stefanie Schröder \\ Higher Education Alliance Ruhrvalley (HAR), Germany; E-Mail: stefanie.schroeder@hs-bochum.de
}

Submitted: 29 March 2021 | Accepted: 14 June 2021 | Published: 16 September 2021

\begin{abstract}
Recent research shows that a remarkable share of refugees who have arrived in Germany over the past few years is highly qualified and has strong educational and academic aspirations. Preparatory colleges (Studienkollegs) and language courses of higher education institutions are the two main organisations providing obligatory study preparation for non-EU international study applicants in Germany, including an increasing number of refugees. So far, research on conditions for refugees' successful transitions into and through study preparation, and eventually into higher education, is scarce. The article fills a research gap on the organisational level by considering the established norms and rules of study preparation organisations and the key role of teachers in shaping successful pathways into higher education. Based on central concepts deriving from the sociology of valuation and evaluation, categorisation, and evaluative repertoires, the article aims to illustrate the organisational norms and rules in play shaping teachers' experiences and perceptions of their students' ability to study. The qualitative analysis of seven expert interviews shows how teachers differentiate between students with and without a refugee background in terms of performance and reveals opportunities and constraints to take refugees' resources and needs in study preparation programmes into account.
\end{abstract}

\section{Keywords}

Germany; organisational rules; refugees; study preparation system; teachers' evaluative repertoires

\section{Issue}

This article is part of the issue "Education, Politics, Inequalities: Current Dynamics and Perspectives" edited by Kenneth Horvath (University of Lucerne, Switzerland) and Regula Julia Leemann (University of Teacher Education FHNW, Switzerland / University of Basel, Switzerland).

(C) 2021 by the author; licensee Cogitatio (Lisbon, Portugal). This article is licensed under a Creative Commons Attribution 4.0 International License (CC BY).

\section{Introduction}

In the sequel of the influx of refugees and asylum seekers since 2015, the German higher education (HE) and study preparation system is facing a new organisational challenge: An increasing number of highly qualified refugees aspire to start or continue studying at German higher education institutions (HEls). For migrants, access to education and especially $\mathrm{HE}$ is of fundamental importance regarding their future social status and participation chances in host countries. HE serves as a stabilising psycho-social intervention and a sustainable basis for refugees to plan a new life (Crea et al, 2015; Morrice, 2013). German HEls and preparatory colleges, the so-called Studienkollegs, initiated support measures and academic preparation programmes for prospective refugee students to respond to the growing demand (Fourier, et al., 2020; in this article, the term "prospective refugee student" is used for asylum applicants participating in measures of study preparation regardless of their current residence status). Yet, research on the role of educational organisations and teachers in the reproduction or transformation of educational inequalities concerning refugees' transition into HEls is still scarce.

Whereas some studies critically investigate institutionalised norms of the (German) academic culture (Baker \& Irwin, 2019; Berg, 2020; Klaus, 2020; Struchholz, 2021; Wojciechowicz, 2018), others have recently evaluated policy barriers to meaningful participation of prospective refugee students (Lenette et al., 2019; Molla, 2020; Stevenson \& Baker, 2018; Unangst, 2019). Also, some case studies investigate institutional reactions and 
frameworks that shape the programmes for refugees (Marcu, 2018; Unangst \& Streitwieser, 2018; Webb et al., 2019) or discuss the opportunities and limits of tailored study preparation offers to respond to refugees' specific resources and needs (Baker et al., 2020). In the German context, studies concentrate on the challenges posed on the governance of HEls (Beigang et al., 2018; Berg et al., 2021; Schammann \& Younso, 2017). However, only a few studies have looked into study preparation while focussing on the microlevel (Grüttner et al., 2018, 2020; Halkic \& Arnold, 2019; Reinhardt et al., 2018). Thus, many research gaps remain, especially in the area of study preparation. In this article, I follow the call to go beyond the issues and problems of refugees (Baker \& Ramsay, 2019) and turn the attention to the organisational level and the role of teachers as important gatekeepers working in obligatory study preparation programmes (Hamann \& Beljean, 2019; Palanc, 2019).

Preparatory colleges and language courses of HEls are the two main organisational frameworks providing obligatory preparation courses for non-EU international study applicants in Germany (Schröder et al., 2019). This article aims at deepening the understanding of study preparation organisations and the role their norms and rules might play in bridging disrupted educational pathways, eventually leading into HEls. In particular, the analysis fills a research gap by considering teachers' experiences and their perceptions of learners and especially refugees in detail. Therefore, I analyse teachers' everyday evaluative practices in study preparation courses. From the perspective of the teachers, I examine how organisational norms and rules are present in their working experiences and influence their leeway in teaching. My main interest is to explore the categorisation criteria underlying teachers' performance assessments and how they evaluate refugee students' "ability to study." I will especially look into teachers' perceptions of (supposed) differences between students with and without a refugee background.

\section{Access Routes and Study Preparation: The Institutional Context in Germany}

The following section is meant to give an introduction to German HE access regulations and study preparation for non-EU international applicants with and without refugee status. Also, I will discuss some implications for prospective refugee students' chances to navigate within this unfamiliar and complex educational environment.

Following Saner's (2019) analysis of admission to art colleges, HE admission generally represents an institutionalised series of tests to evaluate and verify the applicants' quality concerning formalised requirements, in which candidates are continuously re-evaluated in various assessment situations. In the German context, refugees, like other international students who gained their HE entrance certificates in non-EU countries, have to prove the equivalence of their qualifications and are thereupon channelled into distinct $\mathrm{HE}$ access routes (Schröder et al., 2019).

If degrees are recognised as "direct higher education entrance qualification" by the Central Office of Foreign Education (ZAB), as established by the Standing Conference of the Ministers of Education and Cultural Affairs (KMK), applicants have to participate in recognised language courses to prove a C1 German language level according to the Common European Framework of Reference for Languages (CEFR) which is defined as a very high level of effective operational proficiency (see Figure 1, left track). These tailored language courses are mostly offered by HEls. International study applicants are admitted to these courses if they can provide a recognised B2 language certificate. The regulations often additionally require passing a standardised German language test. Admitted students complete these language courses by passing an accredited final assessment test and thereby meet the formal requirements for admission at a HEl.

Applicants who are denied the equivalent qualifications (the "indirect higher education entrance qualification"; see Figure 1, right track) have to prove not only their language skills but also their "subject-specific ability to study." Therefore, they have to attend study preparation courses of so-called Studienkollegs. Since there are limited places in these courses, they have first to pass an entrance examination encompassing language tests in German and, depending on the desired subject, mathematics. The special-subject courses usually take one year and prepare the course participants for the final exam, an accredited German C1 and subject-specific assessment test. By passing the final exam, applicants fulfil the requirements to apply for admission at a HEl.

However, as almost all German HEls have limited capacities in the popular subjects, it is actually a matter of grades if successful participants of study preparation courses, regardless of what track they have to follow, are finally admitted to their favourite study programmes. This holds true for desired subjects like medicine and pharmacy, veterinary medicine, and dentistry ("national admission restrictions" according to the German Rectors' Conference) or, depending on the respective $\mathrm{HEI}$, even electrical or mechanical engineering and other technical subjects.

Especially for prospective refugee students, proving the equivalent subject- and language-specific "ability to study" can become an arduous process (Dippold et al., 2021; Hirano, 2014; Kanno \& Varghese, 2010). Like their fellow international applicants without a refugee background, they are channelled into these routes, which can be characterised as a process of multiple selections. Each step poses a risk of failure and raises questions about whether they can ever achieve their academic goals. Every step requires a considerable transfer of cultural, social, and economic capital as well as appropriate information and guidance to navigate an unfamiliar education system (Bajwa et al., 2017; Cin \& Doğan, 2020). Moreover, anchored in the lasting impact of this 
Evaluation of non-EU international students' HE entrance certificates and obligatory study preparation on the direct (left track) and indirect (right track) access route

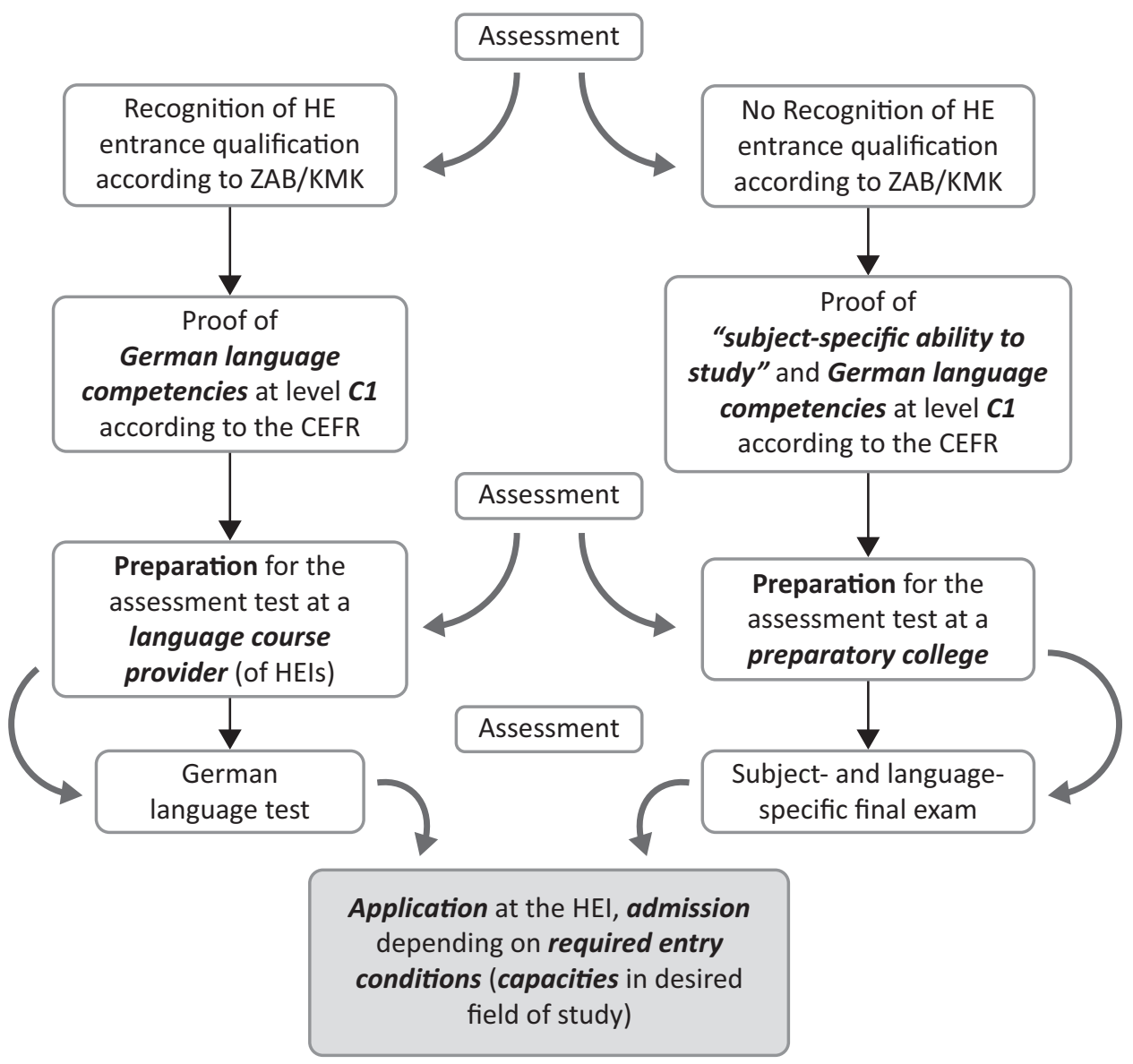

Figure 1. Evaluation process of non-EU international students' $\mathrm{HE}$ entrance certificates and obligatory study preparation on the direct and indirect access route. Notes: ZAB stands for Central Office for Foreign Education; KMK is that Standing Conference of the Ministers of Education and Cultural Affairs; CEFR stands for Common European Framework of Reference for Languages. Source: Own graphic following Lower Saxony Ministry of Science and Culture (2021).

migration channel, which "creates specific opportunities and constraints for migrants" (Sandoz, 2018, p. 224), refugees' pathways to $\mathrm{HE}$ are further shaped by intersecting legal, institutional and social contexts, dependencies and connected resources in the host country (Berg, 2018; Détourbe \& Goastellec, 2018; Sontag, 2019). This specific social position often leads to an amplification of barriers whereby refugee students are particularly disadvantaged (Lambrechts, 2020).

\section{Heuristic Framework: How to Conceptualise Teachers' Assessments in Study Preparation?}

The terms and concepts used in this article and in the following analysis are not oriented towards formal theories in the sense of determining causes and effects, but rather provide a heuristic for the systematic description and explorative analysis of teachers' evaluations in study preparation, as well as the standards and criteria for these evaluations and the teachers' ideas about their legitimacy. In particular, the analysis focuses on the subjective perceptions, experiences, and interpretations of teachers in study preparation courses concerning learners with and without flight experience. Based on a qualitative analysis of expert interviews, I will investigate which criteria teachers use to distinguish between the performance, abilities, and personal characteristics of these two groups of learners.

For this purpose, the analysis is guided by concepts deriving from the programmatical foundation of sociology of valuation and evaluation (SVE) by Lamont (2012). To come closer to the research goal of understanding (e)valuative practices, SVE is particularly concerned with the question of how everyday acts of value ascription and evaluation establish and stabilise orders (Krüger \& Reinhart, 2016), but also how prevailing orders might be irritated to potentially reduce or even overcome social inequalities (Lamont, 2012). Evaluative practices are omnipresent in HE systems, be it in benchmarking processes, excellence initiatives, or, as shown in the previous section, in recognition procedures to determine equivalence of formal access qualifications and in 
admission and selection procedures of HEls. Evaluation is founded on practice- and experience-based social and cultural processes that usually involve intersubjective agreements on referents for the comparison of entities such as goods, characteristics of particular persons or social groups, the negotiation of criteria and legitimate actors for their application, and relational approaches to distinguishing these entities (Lamont, 2012, p. 205). I assume that key concepts of SVE, categorisation and legitimation as central "sub-processes of (e)valuation" (Lamont, 2012, p. 206), are appropriate for analysing the tension between established organisational norms and rules, evaluators' perceptions, experiences, and interpretations, and their everyday actions and decisions. Studying how categorisation and legitimation, as social and cultural processes that vary between contexts, are brought into practice can provide insights into how "evaluative repertoires" are constructed by social actors (Pernkopf et al., 2011, p. 953, following the argumentation of Michelle Lamont on national evaluative repertoires). As Lamont (2019, pp. 116-117) further points out, the notion of repertoire refers to intersubjective, shared bodies of knowledge that actors draw on to assess their environment and to act sensibly in it.

Therefore, the analysis uses the two fundamental assessment situations in pre-study programmes, the admission test and the final exam, as starting points to look into the criteria the teachers apply to categorise the performance, skills, and personal characteristics of their learners. Since teachers have to make difficult decisions concerning their students' transitions with the potential to influence educational trajectories (Maier, 2016), I will explore if and how they rely on organisational norms and rules in their evaluative practices. Especially in admission and selection processes of HEls "contingencies of value" are continually negotiated, as Strandvad (2014, p. 138) points out, and substantiates the influence of organisationally structured social interactions on "how people do things and thus how values and conventions become installed and maintained." Considering teachers' everyday practices, Horvath (2019, p. 125) shows how they use social categorisation criteria in making pedagogical distinctions and points out that "these constructions of differences are embedded in organisational and institutional arrangements of the educational system." Furthermore, I am interested in teachers' interpretations and reasoning when reflecting on their evaluative practices beyond the standardised assessment situations, especially in their everyday perceptions of and interaction with learners. I assume that such patterns of interpretation and reasoning (in the analysis, I refer to them as "teaching standards"), also contribute to the construction of evaluative repertoires in the sense that they regulate professional practices in educational organisations and influence teachers' everyday actions and decisions (Cuadra et al., 2017).

By looking into how teachers apply categorisation criteria in assessing their students' "ability to study," it is, therefore, possible to identify the evaluative repertoires of teachers working in study preparation organisations. As the research focus of this article is to analyse how these evaluative repertoires might shape refugees' pathways through study preparation and into $\mathrm{HE}$, I will use this framework to show how teachers differentiate between students with and without a refugee background in terms of assessment and how they contribute to the social construction of refugee students' ability to study in their everyday actions.

\section{Data, Methods, and Analysis}

The following qualitative analysis is based on data provided by the project "Refugees on Their Way Into German Higher Education" (WeGe). Fourteen expert interviews (Bogner \& Menz, 2009) were conducted in late 2019 in the two main organisational types of study preparation for non-EU international students in Germany: language course providers, representing the track of direct HE entrance qualifications (eight experts), and special subject courses of Studienkollegs, representing the track of indirect $\mathrm{HE}$ entrance qualifications (six experts). To establish contact with potential interview partners, I reached out to contact partners from study preparation organisations in which a quantitative survey of course participants had already been realised within the framework of the research project. All experts are experienced professionals and hold managing as well as teaching positions. For the following analysis, the original sample was reduced to the seven interviews with teachers working in Studienkollegs (three interviews) and language course providers of HEls (four interviews). Professionally, the experts have an academic background as teachers, mainly of German or German as a foreign language, while two (also) teach mathematics.

For the interviews with the teachers, I used a prestructured interview guideline (Gläser \& Laudel, 2010) which aimed to generate ex-post narrations with a focus on professional experience in teaching within the context of study preparation. Among other issues, the first part of the interview guideline addresses the experts' experience with the course participants in different areas at the level of day-to-day interactions. The second part of the interview guideline was focused on their experiences with the increasing proportion of refugees in the courses as well as on organisational changes concerning the teaching of refugees.

For the qualitative content analysis (Mayring, 2004), the expert interviews were coded based on a preliminary system of categories with a focus on the following analytical questions: (1) How do the teachers relate standards of evaluating the students' "ability to study" to the norms and rules of the organisation? (2) What "evaluative repertoires" can be identified based on the categorisation criteria the teachers apply in their assessments? (3) What does that mean for shaping refugee students' transitions to HEls? 
The coding was orientated at "gradual category formation" (Mayring, 2004, p. 268) from the material by identifying which codes have to be subsumed under existing categories or are to be developed into new categories. In the first step, the coding was concentrated on revealing patterns in the teachers' narrations of their everyday experiences concerning assessment situations in their organisation. In the second step, I shifted the coding focus to the standards they refer to in their evaluation of the students' "ability to study" and how they relate them to organisational norms and rules. In the next step, I applied the dimensions "categorisation criteria" and "evaluative repertoires" as sensitising concepts to systemise the categorisation patterns the teachers rely on in evaluating the students within and beyond the standardised assessment situations, especially in their everyday perceptions of and interaction with learners. The last coding step was focused on the significance of a refugee background in the teachers' evaluation of their students' "ability to study" and developed the network of relationships (Böhm, 2004) between the sequences entailing the teachers' narrations on how they experience refugee students in comparison to their fellow course participants without a refugee background.

\section{Investigating Assessments: The Interplay of Organisational Rules and Teaching Standards}

Both assessment situations, the admission test and the final exam, represent the fundamental goals of the study preparation organisations to recruit and select students in line with the established formal requirements for study applicants with non-EU HE entrance qualifications. As the professional practice of the teachers is especially concerned with providing an appropriate study preparation, it is possible to look into the standards they refer to in their evaluation of the students' "ability to study" and how these are related to organisational norms and rules on the one hand and to their everyday experience of and interaction with learners on the other.

The organisational capacities in study preparation result from the financial resources and the accordingly available teaching staff as well as the actual number of applications. Therefore, admission depends on the applicants' results in the entrance assessment and the current course capacities. The teachers notice that due to restricted capacities, highly qualified applicants still have to be rejected, as one teacher explains: "There are really many, many applicants who do very, very well in the admission test but nonetheless we have to reject even excellent students due to limited capacities in the courses" (translation by the author).

Overall, the teachers tend to think of admission regulations as legitimate. The admission test can serve as an instrument that mediates between restricted financial capacities and the standard of "fairness," as this quote reveals: "We rank the performance and we admit the applicants on this basis. I find our system fair and ade- quate. This way the maximum number of course participants will be 25 . We do not admit more than 25."

Despite this standardised procedure in the admission process the teachers tend to assess the performance of the students as heterogeneous. They strive to adjust the lessons and to reduce the heterogeneity, as this teacher points out:

Even if I differentiate between individual start conditions, it does not always work out in 90 minutes to satisfy the requirements of all the different learning cultures and learning styles. Generally speaking, these different conditions are permanently impeding my teaching.

In the view of the teachers, the regulation of the final exam ensures that successful course participants fulfil the performance standards in line with the formal requirements of HEls in terms of the languageand subject-specific "ability to study." HEls normally specify which certificates are accepted for admission. In response to these requirements, the teachers adjust their lessons to prepare the students as appropriately as possible to pass the final exam, as this teacher states:

That is a fact and I have to take that into account. Therefore, we have to modify contents [and], if necessary, processes and scopes, and so on, to observe the next step, in our case the next educational step at university.

The significance of the assessment situations reflects how teachers' experiences and actions are influenced not only by personal assessment standards but at the same time by organisational norms and rules. Besides positive opinions, neutral statements, as well as critical positions, can be found in terms of legitimate standards for evaluative practices in the context of study preparation. However, the teachers share the experience to only influence how they develop their lessons rather than change the admission rules of pre-study programmes or HEls. In particular, they criticise limited opportunities for individual support and responding to the students' heterogeneous needs during their lessons. Fulfilling the established performance standards seems to be rather a question of capacities than one of prior qualifications. Overall, the teachers rarely refer to learners in their narrations on the key assessment situations, the entrance exam and the final exam. Furthermore, it remains unclear how they differentiate between learners, they rather refer to learners in general.

\section{Categorisation Criteria and Evaluative Practices: Exploring Evaluative Repertoires of Teachers}

In the coding procedure, a set of categorisation criteria emerged, which was on the one hand connected to performance-based, "formal accounts" (Hasse, 2015, 
pp. 56-59), in terms of learners' language- and subjectspecific "ability to study." At the same time, the teachers use criteria that refer to "collective accounts" (Hasse, 2015, pp. 59-62) as a form of individual-case based argumentation to justify their pedagogical distinctions. Both can be seen as interpretative patterns available to teachers to explain their perceptions and decisions towards relevant others (Hasse, 2015, p. 56). Concerning the teachers' everyday experiences of the students' performance and how it can be evaluated, both forms of accounts are closely intertwined. In the following, I illustrate how their understanding of learners' resources, necessary for successful study preparation, is informed by experience-based assumptions of appropriate learning skills and conditions for successful learning in general. In this regard, they do not distinguish between refugees and learners without refugee experience.

The teachers refer to the respective education system of the home country to distinguish between students' performances during the course, as this quote shows: "And in chemistry, there is quite a wide range, how many chemistry lessons they took in their home countries....Often, these are the structures that were common in the home countries."

In addition, this reference to the education system encompasses not only subject-specific competencies but also the level of German language competency and foreign language skills in general:

I mean the grades of the school leaving certificates are not comparable. They are different, actually, in mathematics, physics, but also the language competencies in German. That is related to the issue of whether I have been confronted with a foreign language at all. And that is important.

From the perspective of the teachers, certain attitudes towards learning and already acquired learning strategies play a key role for successful learning in German study preparation courses: "Facts are learned. They do not learn how to learn, how to continue learning, how to learn independently, alone, how to learn autonomously, how to gain knowledge autonomously."

In addition, some teachers tend to relate their interpretations of the home country education system to the supposed cultural contexts they are embedded in, as this quote shows:

In terms of discipline and self-organisation, I think, in general, discipline is rooted more firmly in East Asia....Occasionally, it can be noticed this "I have to struggle through. Maybe I am not really interested, but I simply have to do it now." That is somewhat stronger pronounced there compared to other cultures.

Following the experiences of the teachers, the students' social resources and especially social relations with the student community are of fundamental importance to make the best possible use of the performance potential. This teacher, for example, views a reliable network and social ties to German-speaking friends and fellow students as a crucial advantage to cope in study preparation: "Social integration. Friends, acquaintances, points of contact, groups. Not to be alone, that surely is important." Another teacher highlights the self-responsibility of the students to make German-speaking friends:

To what extent they are not exclusively with their community but realise that it is helpful to join a university's sports group, if they talk to neighbours speaking other languages, other native speaking languages and somehow recognise not to stay solely with their community... therefore, accepting [that] "I have to establish contact [with] the German language and at university." That also is important.

The teachers tend to use the same evaluative repertoire orientated on meritocratic approaches when they explain the necessity to repeat courses or to drop out of study preparation. Following the experience of this teacher, failing generally derives from individual decisions and responsibilities:

We only provide intensive courses. That is five or six lessons daily, 25 or 30 lessons weekly. That is quite a great challenge. Yes. That has to be faced. As a participant, you have to know that. And you have to want it. Therefore, this will to successfully master this.

This quote additionally reflects the perception that sequences and structures of the courses cannot simply be adapted. They are rather interpreted as important and transparent information for course participants on how to successfully prepare for studying.

Overall, the teachers tend to legitimise the established course structures by arguing that they are solely aiming at an appropriate study preparation. At the same time, they seem to be aware of social and cultural prerequisites influencing successful study preparation. The following quote illustrates this position: "Therefore, we can provide an offer. But a professional offer. Yet, the person has to have this will and the competencies to accept this offer and further develop it." From this perspective, teachers are on the one hand dedicated to the goal to successfully prepare their students for studying. On the other hand, the analysis points to the significance of prerequisites to achieve the expected level of language and subject-specific proficiency.

\section{Evaluative Repertoires of Teachers and Their Influence on Refugees' Study Preparation}

As shown in the previous section, the categorisation criteria teachers apply in their everyday evaluations, without clearly distinguishing between refugees and other 
international students, emphasise the significance of various prerequisites influencing successful study preparation. In the following, I illustrate how they relate to this evaluative repertoire when it comes to potential differences between students with and without flight experience. The teachers use a categorisation pattern that is orientated at meritocratic justifications of performance differences encompassing individual skills and social prerequisites, which seems contradictory only at first glance.

Overall, the teachers highlight the heterogeneity in terms of performance characterising both groups. However, the teachers' narrations reflect that they are aware of special barriers refugees face while transitioning into HE. From the perspective of the teachers, these barriers obviously influence refugees' chances to successfully prepare for studying: "And the pace is another substantial problem that I generally notice regarding refugees. That many who understood everything correctly, are simply slower, definitely slower than most of the other regular applicants."

In general, the teachers observe slower progress of refugees in study preparation and identify a higher risk to repeat the courses. They tend to interpret these performance differences as a consequence of flight-specific psychological problems, as this teacher points out:

The psychological effects of this life change, the flight, this completely different environment, this entirely different culture. Language, religion and so on, above all do not fail to leave their mark on these young people. That needs to be stated.

Furthermore, the teachers highlight that refugees are exposed to social marginalisation and social risks deriving from restricted everyday living conditions and the complex obligations linked to the refugee status. This is viewed as an additional risk to fail in study preparation.

Also, as we have seen in the teachers' legitimations of the admission test, prior language learning is of fundamental importance to get a place in study preparation courses. This aspect is directly related to the issue of how asylum authorities are dealing with the academic aspirations of refugees. Refugees are obliged to participate in so-called integration courses that lack a particularly academic orientation, as this teacher criticises:

For example, in these integration courses there is a wild mix of people, many different levels, the course books are bad and there is no academic standard. Then it is definitely hard to achieve this level that is necessary to be up to the task here.

Despite these differences, the teachers strongly emphasise that all students have to be treated equally. At the same time, they highlight their individual responsibility to provide the learning environment they deem appropriate for successful study preparation. This personal standard links the "evaluative repertoire" teachers apply in assessment practices to their actions and decisions in courses:

And I strive to tend to everybody as best I can to lead them to their studies. I mean, I fight for the students so that they are able to walk this path on their own. I can only guide them. Everything else is up to them. And I make no difference in this regard.

But still, even if teachers show a wide range of responses to the special needs of refugees, they refuse to question the organisational norms and rules in which the courses are embedded:

As a teacher, one always wishes to bring everybody on board; on the other hand you have to ensure professional study preparation. This is to say, I cannot lower the pace at random because l'll risk not being able to cover all the necessary subject matters.

The teachers' narrations reveal the dilemma that "fair" assessment is sometimes not fair enough (if ever possible). This dilemma seems to be exacerbated in the case of evaluating the performance of prospective refugee students. While most of the teachers are aware that the performance of refugees necessitates specific prerequisites but feel they have no options to provide responsive supports, some seem to have developed stereotypical expectations concerning legitimate performance standards that all learners have to meet, regardless of a potential refugee background. Overall, the analysis points to the significance of a meritocratic legitimation of evaluative practices, a position that is likely to individualise and essentialise social inequalities.

\section{Conclusions}

The analysis reveals that the organisational norms and rules of selecting and preparing applicants in terms of access to HEls are indeed present in the teachers' everyday actions and decisions and tend to guide their evaluation of learners. The formal rules of the organisation determine what is to be assessed as appropriate "ability to study" and teachers give practical effect to these rules by mediating "teaching standards" and their perceptions of student performance in their evaluative practices. What is more, the analysis shows that teachers rely on social categorisation criteria in making distinctions in terms of performance evaluations. This finding points to the notion of "evaluative repertoires" (Lamont, 2019; Pernkopf-Konhäusner \& Brandl, 2011) and the role of fundamental categorisation patterns in the social (re-)construction of educational inequalities (Horvath, 2019). However, following Maier (2016), it has to be noted that teachers have the professional obligation to make distinctions and therefore it is not surprising that they tend to justify performance differences in line with 
prevailing pedagogic standards that are orientated on a meritocratic legitimation strategy.

Concerning the evaluation of refugees' performance in study preparation, the analysis of the "evaluative repertoire" highlights the significance of this dominant categorisation pattern: The teachers' claim that all students have to be treated equally points to the importance of social standards like "fairness" in their everyday professional practices. Yet, while the teachers recognise performance differences between students based on a refugee background, they struggle to take into account special needs and educational barriers linked to refugees' experiences of flight and social positioning in their "evaluative repertoire." Eventually, the teachers tend to expect them to meet the same standards as their fellow course participants without a refugee background, thus legitimising the overarching organisational norms and rules represented in the "assessment chain" (Saner, 2019) of study preparation and admission to HEls in Germany-an understanding that obviously does not irritate existing reproduction patterns of educational or social inequalities.

The present analysis shows that teachers in German study preparation face limitations while striving to respond to social inequalities related to refugee status. Diminishing the competitive character of the multiple selection process to HE is most likely to widen teachers' opportunities to provide responsive support for refugees. Possible measures to overcome such structural restrictions might therefore include expanding the capacities of Studienkollegs and language course providers at HEIs as well as sustainable funding for refugees and asylum policy-change allowing for delays and detours during study preparation. Also, professional training strategies for teachers might provide frameworks for systematic reflection on established "evaluative repertoires" and initiate local engagements to further develop pre-study programmes responding to the specific learning conditions of refugees. Unfortunately, the working conditions of teachers in pre-study programmes were not the focus of this analysis. However, based on the talks accompanying the expert interviews, it can be problematised that many teachers are precariously employed and comparatively poorly paid. Temporary and honorary contracts are widespread. Such employment conditions only render the motivation and voluntary engagement of teachers to a limited extent, especially when it comes to participating in additional professional training. What is more, the search for innovative equity strategies should not only focus on teaching staff or the support structures and offers of study preparation organisations anyway. Successful post-migration trajectories rather rely on political engagement encompassing institutions throughout the relevant policy areas that are shaping refugees' educational trajectories and life chances.

I will now take the liberty of making one last comment for the current occasion of the Covid-19 pandemic: Prospective refugee students particularly benefit from experiences of social integration, which goes hand in hand with social recognition and appreciation in study preparation programmes (Grüttner, 2019). Existing educational inequalities are likely to be exacerbated in the course of the pandemic. This once again emphasises the urgent need to enhance responsive supports for refugees in German HE and study preparation.

\section{Acknowledgments}

The project "Refugees on Their Way into German Higher Education" (WeGe) was funded by the Federal Ministry of Education and Research as part of the "Academic Success and Dropout Phenomena I" funding line (Grant: 01PX16015). I would like to thank all of the participants in our study, experts as well as prospective refugee students, who were willing to share their experiences with the members of the research team. Especially, I would like to thank my former colleagues at the German Centre for Higher Education Research and Science Studies (DZHW) Jana Berg, Michael Grüttner, Carolin Otto, Olivia Laska, and Sebastian Zühl for always supporting me in following my research interests.

\section{Conflict of Interests}

The author declares no conflict of interest.

\section{References}

Bajwa, J. K., Couto, S., Kidd, S., Markoulakis, R., Abai, M., \& McKenzie, K. (2017). Refugees, higher education, and informational barriers. Refuge, 33(2), 56-65.

Baker, S., \& Irwin, E. (2019). Disrupting the dominance of 'linear pathways': How institutional assumptions create 'stuck places' for refugee students' transitions into higher education. Research Papers in Education, 12(1), 1-21. https://doi.org/10.1080/02671522. 2019.1633561

Baker, S., \& Ramsay, G. (2019). Higher education and students from refugee backgrounds: A metascoping study. Refugee Survey Quarterly, 38(1), 55-82. https://doi.org/10.1093/rsq/hdy018

Baker, S., Irwin, E., \& Freeman, H. (2020). Wasted, manipulated and compressed time: Adult refugee students' experiences of transitioning into Australian higher education. Journal of Further and Higher Education, 44(4), 528-541. https://doi.org/10.1080/0309877X. 2019.1586849

Beigang, S., von Blumenthal, J., \& Lambert, L. (2018). Studium für Geflüchtete: Aufgaben für Hochschulen und Politik (Policy Brief 08b) [Studies for refugees: Tasks for universities and politics]. Flucht: Forschung und Transfer. https://flucht-forschung-transfer.de/ wp-content/uploads/2018/04/PB-08b-04-2018.pdf

Berg, J. (2018). A new aspect of internationalisation? Specific challenges and support structures for refugees on their way to German higher education. In A. Curaj, 
L. Deca, \& R. Pricopie (Eds.), European higher education area: The impact of past and future policies (pp. 219-235). Springer. https://doi.org/10.1007/978-3319-77407-7_15

Berg, J. (2020). Which person is presumed to fit the institution? How refugee students' and practitioners' discursive representations of successful applicants and students highlight transition barriers to German higher education. In A. Curaj, L. Deca, \& R. Pricopie (Eds.), The future of higher education: Bologna process researchers' conference 2020. Springer. https:// doi.org/10.1007/978-3-030-56316-5_15

Berg, J., Gottburgsen, A., \& Kleimann, B. (2021). Formalising organisational responsibility for refugees in German higher education: The case of first contact positions. Studies in Higher Education. Advance online publication. https://doi.org/10.1080/03075079. 2021.1872524

Bogner, A., \& Menz, W. (2009). The theory-generating expert interview: Epistemological interest, forms of knowledge, interaction. In A. Bogner, B. Littig, \& W. Menz (Eds.), Interviewing experts. Research methods series (pp. 43-80). Palgrave Macmillan. https://doi. org/10.1057/9780230244276_3

Böhm, A. (2004). Theoretical coding: Text analysis in grounded theory. In U. Flick, E. von Kardorff, \& I. Steinke (Eds.), A companion to qualitative research (pp. 270-275). SAGE.

Cin, F. M., \& Doğan, N. (2020). Navigating university spaces as refugees: Syrian students' pathways of access to and through higher education in Turkey. International Journal of Inclusive Education. Advance online publication. https://doi.org/10.1080/ 13603116.2019.1707309

Crea, T. M., Calvo, R., \& Loughry, M. (2015). Refugee health and wellbeing: Differences between urban and camp-based environments in sub-Saharan Africa. Journal of Refugee Studies, 28(3), 319-330. https:// doi.org/10.1093/jrs/fev003

Cuadra, D., Castro, P. J., Vystrcilová, \& Mogliacci, R. J. (2017). A review of research on teachers' subjective theories. Contributions to the study of teacher education. Psychology and Education Journal, 54(3), 1-22.

Détourbe, M.-A., \& Goastellec, G. (2018). Revisiting the issues of access to higher education and social stratification through the case of refugees: A comparative study of spaces of opportunity for refugee students in Germany and England. Social Sciences, 7(10). https://doi.org/10.3390/socsci7100186

Dippold, D., Heron, M, \& Gravett, K. (2021). International students' linguistic transitions into disciplinary studies: A rhizomatic perspective. Higher Education. Advance online publication. https://doi.org/ 10.1007/s10734-021-00677-9

Fourier, K., Prado, E., \& Grüttner, M. (2020). Integration von Flüchtlingen an deutschen Hochschulen. Erkenntnisse aus den Hochschulprogrammen für Flüchtlinge [Integration of refugees at German universities.
Findings from higher education programmes for refugees]. DAAD. https://static.daad.de/media/ daad_de/pdfs_nicht_barrierefrei/p43_gefluechtete_ teil3_rz_web.pdf

Gläser, J., \& Laudel, G. (2010). Experteninterviews und qualitative Inhaltsanalyse als Instrumente rekonstruierender Untersuchungen [Expert interviews and qualitative content analysis as instruments of reconstructive studies]. Springer.

Grüttner, M. (2019). Belonging as a resource of resilience: Psychological wellbeing of international and refugee students in study preparation at German higher education institutions. Student Success, 10(3), 36-44. https://doi.org/10.5204/ssj.v10i3.1275

Grüttner, M., Schröder, S., \& Berg, J. (2020). Erfolgserwartung und Abbruchneigung bei internationalen Studieninteressierten und Geflüchteten in der Studienvorbereitung [Expectations of success and dropout intentions among international study applicants with and without refugee background in study preparation]. In M. Jungbauer-Gans \& A Gottburgsen (Eds.), Migration, Mobilität und soziale Ungleichheit in der Hochschulbildung [Migration, mobility and social inequality in higher education] (pp. 169-196). Springer.

Grüttner, M., Schröder, S., Berg, J., \& Otto, C. (2018). Refugees on their way to German higher education: A capabilities and engagements perspective on aspirations, challenges and support. Global Education Review, 5(4), 115-135.

Halkic, B., \& Arnold, P. (2019). Refugees and online education: Student perspectives on need and support in the context of (online) higher education. Learning, Media and Technology, 44(3), 345-364. https:// doi.org/10.1080/17439884.2019.1640739

Hamann, J., \& Beljean, S. (2019). Career gatekeeping in cultural fields. American Journal of Cultural Sociology, 9, 43-69. https://doi.org/10.1057/s41290-01900078-7

Hasse, R. (2015). Organisationssoziologische Bildungsanalysen. Eine Situationseinschatzung [Organisational sociological analyses of education. A situation assessment]. In R. J. Leemann, C. Imdorf, J. J. W. Powell, \& M. Sertl (Eds.), Die Organisation von Bildung. Soziologische Analysen zu Schule, Berufsbildung, Hochschule und Weiterbildung [The organisation of education. Sociological analyses of school, vocational training, higher education and further education] (pp. 47-65). Juventa.

Hirano, E. (2014). Refugees in first-year college. Academic writing challenges and resources. Journal of Second Language Writing, 23, 37-52. https://doi. org/10.1016/j.jslw.2014.01.001

Horvath, K. (2019). Unterschiede, Ungleichheiten, Unterscheidungen. Pädagogisches Kategorisieren zwischen Engagement, Rechtfertigung und Kritik [Differences, inequalities, distinctions. Pedagogical categorisation between engagement, justification 
and critique]. In C. Imdorf, R. J. Leemann, \& P. Gonon (Eds.), Bildung und Konventionen. Die "Economie des Conventions" in der Bildungsforschung [Education and conventions. The "Economie des Conventions" in educational research] (pp. 121-144). Springer.

Jungblut, J., Vukasovic, M., \& Steinhardt, I. (2018). Higher education policy dynamics in turbulent times: Access to higher education for refugees in Europe. Studies in Higher Education, 45(2), 327-338. https://doi.org/ 10.1080/03075079.2018.1525697

Kanno, Y., \& Varghese, M. M. (2010). Immigrant and refugee ESL students' challenges to accessing fouryear college education. Journal of Language, Identity \& Education, 9(5), 310-328.

Klaus, S. (2020). Biographische Konstruktionen zur Ambivalenz von Hochschulzugang und Fluchthintergrund. "Ich bin nicht der richtige sogenannte Flüchtling" [Biographical constructions on the ambivalence of university access and refugee background. "I am not the right so-called refugee"]. Springer.

Krüger, A. K., \& Reinhart, M. (2016). Wert, Werte und (Be)Wertungen. Eine erste begriffs- und prozesstheoretische Sondierung der aktuellen Soziologie der Bewertung [Value, values and (e)valuations. A first conceptual and process-theoretical exploration of the current sociology of valuation]. Berliner Journal für Soziologie, 26, 485-500. https://doi.org/10.1007/ s11609-017-0330-x

Lambrechts, A. A. (2020). The super-disadvantaged in higher education: Barriers to access for refugee background students in England. Higher Education. Advance online publication. https://doi.org/ 10.1007/s10734-020-00515-4

Lamont, M. (1992). Money, morals \& manners: The culture of the French and the American upper-middle class. University of Chicago Press.

Lamont, M. (2012). Toward a comparative sociology of valuation and evaluation. Annual Review of Sociology. Advance online publication. https://doi.org/ 10.1146/annurev-soc-070308-120022

Lamont, M. (2019). Evaluierungskriterien und kulturelle Strukturen [Evaluation criteria and cultural structures]. In S. Nicolae, M. Endreß, O. Berli, \& D. Bischur (Eds.), (Be)Werten. Beiträge zur sozialen Konstruktion von Wertigkeit $[(\mathrm{E})$ valuing. Contributions to the social construction of value] (pp. 113-124). Springer Nature.

Lenette, C., Baker, S., \& Hirsch, A. (2019). Systemic policy barriers to meaningful participation of students from refugee and asylum seeking backgrounds in Australian higher education. Neoliberal settlement and language policies and (deliberate?) challenges for meaningful participation. In J. L. McBrien (Ed.), Educational policies and practices of English-speaking refugee resettlement countries (pp. 88-109). Brill; Sense.

Lower Saxony Ministry of Science and Culture. (2021).
Hochschulzugänge für Flüchtlinge [University access for refugees]. https://www.mwk.niedersachsen.de/ startseite/hochschulen/studium/hochschulzugang_ gefluechtete/hochschulzugaenge-fuer-fluechtlinge134615.html

Maier, M., (2016). Die Prozessierung schulischer Selektion [The processing of selection in school]. In $\mathrm{M}$. Maier (Ed.), Organisation und Bildung [Organisation and education] (pp. 139-160). Springer.

Marcu, S. (2018). Refugee students in Spain. The role of universities as sustainable actors in institutional integration. Sustainability (Switzerland), 10(6). https:// doi.org/10.3390/su10062082

Mayring, P. (2004). Qualitative content analysis. In U. Flick, E. V. Kardoff, \& I. Steinke (Eds.), A companion to qualitative research (pp. 266-269). SAGE.

Molla, T. (2020). Refugees and equity policy in Australian higher education. Policy Reviews in Higher Education, 5(1). https://doi.org/10.1080/23322969.2020. 1806727

Morrice, L. (2013). Refugees in higher education. Boundaries of belonging and recognition, stigma and exclusion. International Journal of Lifelong Education, 32(5), 652-668. https://doi.org/10.1080/02601370. 2012.761288

Palanc, A. (2019). Renaissance of the gatekeepers. Establishing a culture of welcome for refugees and asylum seekers at the University of Leicester's English language teaching unit. Language Learning in Higher Education, 9(1), 117-125. https://doi.org/10.1515/ cercles-2019-0006

Pernkopf-Konhäusner, K., \& Brandl, J. (2011). Variations in evaluative repertoires. Comparing employee perspectives on training and development in Germany and Russia. Personnel Review, 40(5), 589-606.

Reinhardt, F., Zlatkin-Troitschanskaia, O., Deribo, T., Happ, R., \& Nell-Müller, S. (2018). Integrating refugees into higher education-The impact of a new online education for policies and practices. Policy Reviews in Higher Education, 2(2), 198-226.

Sandoz, L. (2018). Understanding access to the labour market through migration channels. Journal of Ethnic and Migration Studies, 66(1), 1-20. https://doi.org/ 10.1080/1369183X.2018.1502657

Saner, P. (2019). Das Unbestimmbare bewerten. Aufnahmeverfahren an Kunsthochschulen aus rechtfertigungstheoretischer Perspektive [Assessing the indeterminable. Admission procedures at art colleges from a justification-theoretical perspective]. In C. Imdorf, R. J. Leemann, \& P. Gonon (Eds.), Bildung und Konventionen. Die "Economie des Conventions" in der Bildungsforschung [Education and conventions. The "Economie des Conventions" in educational research] (pp. 179-203). Springer.

Schammann, H., \& Younso, C. (2017). Endlich Licht in einer dunklen Ecke? Hürden und Angebote für Geflüchtete im tertiären Bildungsbereich [Light at last in a dark corner? Barriers and offers for refugees 
in the tertiary education sector]. Zeitschrift für internationale Bildungsforschung und Entwicklungspädagogik, 40(1), 10-15.

Schröder, S., Grüttner, M., \& Berg, J. (2019). Study preparation for refugees in German 'Studienkollegs'Interpretative patterns of access, life-wide (language) learning and performance. Widening Participation and Lifelong Learning, 21(2), 67-85. https://doi.org/ 10.5456/WPLL.21.2.67

Sontag, K. (2019). Refugee students' access to three European universities: An ethnographic study. Social Inclusion, 7(1), 71-79. http://dx.doi.org/10.17645/si. v7i1.1622

Stevenson, J., \& Baker, S. (2018). Refugees in higher education. Debate, discourse and practice. Emerald Publishing.

Strandvad, S. M. (2014). Contingencies of value. Devices and conventions at a design school admission test. Valuation Studies, 2(2), 119-151. https://doi.org/ 10.3384/vs.2001-5992.1422119

Struchholz, C. (2021). Geflüchtete im deutschen Hochschulsystem. Eine Grounded-Theory-Studie zum Bildungserleben Studierender mit Fluchthintergrund [Refugees in the German higher education system. A grounded theory-study on the educational experience of students with a refugee background]. transcript.

Unangst, L. (2019). Refugees in the German higher education system: Implications and recommendations for policy change. Policy Reviews in Higher Education, 3(2), 144-166.

Unangst, L., \& Streitwieser, B. (2018). Inclusive practices in response to the German refugee influx: Support structures and rationales described by university administrators. In R. Pricopie, L. Deca, \& A. Curaj (Eds.), European higher education area: The impact of past and future policies (pp. 287-300). Springer.

Webb, S., Dunwoodie, K., \& Wilkinson, J. (2019). Unsettling equity frames in Australian universities to embrace people seeking asylum. International Journal of Lifelong Education, 38(1), 103-120.

Wojciechowicz, A. (2018). Erkämpfte Hochschulzugänge in der Migrationsgesellschaft. Rassismuskritische Perspektiven auf Biografien von Lehramts- und Jurastudentinnen [Struggle for access to higher education in the migration society. Racism-critical perspectives on the biographies of female teacher and law students]. Springer.

\section{About the Author}

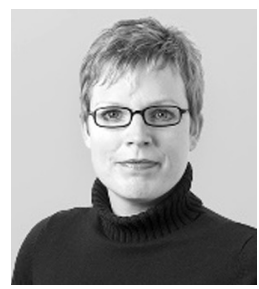

Stefanie Schröder is the coordinator for academic continuing education the Higher Education Alliance Ruhrvalley (HAR)-Consortium of Universities of Applied Sciences in the Ruhr Area. Before that, she was a researcher at the German Centre for Higher Education Research and Science Studies (DZHW) in Hannover, Germany, most recently in the project "Refugees on Their Way Into German Higher Education." Her research and work focus on education and social inequality, alternative access to $\mathrm{HE}$, and innovative study formats. 